\title{
Agricultural Development In Nigeria: Communicating The Roles Of National Universities
}

\author{
Abdulhameed Kayode Agboola \\ Department of Information and Media TechnologySchool of Information and Communication Technology \\ Federal University of Technology, Minna, NIGERIA
}

\begin{abstract}
Studies have raised many mind bungling issues as to the reason why agriculture has yet to manifest all the great things that were prophesied by its proponents in terms of national development. It is a fact that the recent decade has been one of agro-optimism just like in the 70s, upon all the promises that agricultural development seems to hold none is yet to come past. It was hoped in the Sub-Saharan Africa that economic development would be brought about by agricultural development. Unfortunately, this optimism is yet to be realized and hope has never been materialized and agricultural productivity did not increase much in SubSaharan Africa. This paper argues that universities have a direct role to play in the socio-development of the agrarian communities in Nigeria in general, if agricultural development is to be informed knowledge-wise and to contribute to community development and poverty alleviation. In this context, the relationship between universities and rural community development must be of important concern. In this regard, this paper elaborates on the role of universities in modern agrarian society development and discusses some possibilities in poverty alleviation, illiteracy reduction, environmental management, teaching and research activities by which they could increase their contribution to the agrarian society and socio-economic development of Nigeria. This paper concludes by suggesting strategies whereby the three wings of the university - extension, teaching and research - can be geared towards the purpose of uplifting the Nigerian society as a whole.
\end{abstract}

Keywords: Agricultural development, rural community, local university, agricultural university, community development

\section{Introduction}

Agriculture is a crucial economic activity, providing employment and livelihoods for many and serving as the basis for many industries. A United Nations Environment Programme (UNEP) report of 2007 highlighted that in the Sub-Saharan Africa countries, about 203 million people, or 56.6 percent of the total labor force, engaged in agricultural activities. Even until date agriculture supports the survival and well-being of majority of the African countries populations (UNEP, 2007, cited in Agboola, 2013). The World Bank has estimated that nearly 800 million people, or roughly 40 percent of the population of the developing nations, still live in absolute poverty; studies indicate that in many instances the poor have not benefited-in-deed, they may have suffered absolute loss-during early stages of national development. In response there has been growing interest in new approaches to national development intended to bring the poor more rapidly into full participation in development decisions, implementation, and benefits (World Development Report, 1978 cited in Korten, 1980).

However, the advocacy for agriculture as a panacea to poverty reduction in developing countries of the world was spread with evangelical zeal by those who found the text compelling and convincing, but contrarily, this advocacy was only in spirit. Therefore, question has been raised, as to the reason why agriculture has yet to manifest all the great things that were prophesied by its proponents. Even though the present decade has been one of agro-optimism, but the promises that agricultural development seems to hold have yet to come past. This pessimism seems to coincide with pessimism about Sub-Saharan Africa in the hope that economic development would be brought about by agricultural development (Meijerink \& Roza, 2007). After the success of the green revolution in Asia, the hope was that a similar agricultural miracle would transform African economies in general. But this hope never materialised, agricultural productivity did not increase much in Sub-Saharan Africa, and worse, the negative effects of the green revolution in Asia became more apparent, such as pesticide overuse and subsequent pollution are now taking their tolls (The World Bank Report, 2008).

\section{The Role Of Agriculture In Modern Society}

Agriculture provides the basis of subsistence for the population by production of food and raw materials. Traditionally, the inhabitants of each country or region depended on the bread-basket filled by the farmers, that is, everybody depended on agriculture and was interested in its fate. In recent times, regional and international trades have reduced the dependence on home agriculture, and the quantity of available food is less a function of the harvest than of the political decision on the amount of food imports (Kuhnen, 1978). 
According to World Development Indicator (2006), agriculture constitutes the main source of employment of the majority of the world's poor. In total, the share of agriculture in total employment in developing countries constitutes 53\% of the total workforce in 2004. In Sub-Saharan Africa 60\% of the economically active population works in the agricultural sector. By the end of the 1950s the experience gained from efforts to promote economic development showed great differences among developing countries. Some had broken away relatively quickly from the import-substitution, government-control and - ownership pattern that had been the early development practice. While others adamantly continued to practice the same policies for several decades. Thus the experiences of different developing countries have created a repository of information and knowledge from which to draw.

But in the mean while, it is a fact that agriculture cannot produce much more without the inputs and services of both secondary and tertiary sectors, even agriculture acts itself as a customer to these other sectors, thus providing work and income outside of agriculture. These changes in agriculture had consequences for the agricultural population. Many people from rural areas migrated to the cities and filled the ranks of workers in the secondary and tertiary sectors. For the remaining rural population, agriculture changed from a way of life to a profession in which technical know-how plays an ever increasing role. Frequently, the structure and organization of the farm changed, for example, new forms like part-time farming arose. In areas with very tiny holdings and poor soil, rural-urban migration reached the stage where only the aged live in the village. Particularly under such conditions, the responsibility of agriculture for the preservation of nature adds to the roles it plays today (Kuhnen, 1978).

However, despite early emphasis on industrialization through import substitution, it was realized that there is a close connection between the rate of growth in the output of the agricultural sector and the general rate of economic development. The high rates of economic growth are associated with rapid expansion of agricultural output and low rates of economic growth with the slow growth of agriculture. This was the expectation, since agriculture forms a large part of the total domestic product and of the exports of the developing countries (Meijerink \& Roza, 2007).

Many far eastern nations were able to expand their agricultural output rapidly by a vigorous pursuit of appropriate policies. These included the provision of adequate irrigation facilities, enabling a succession of crops to be grown on the same piece of land throughout the year; the use of high-yielding seeds and fertilizers, which raised the yields per acre in a dramatic fashion; provision of adequate incentives for producers by setting producer prices at reasonable levels; and improvements in credit and marketing facilities and a general improvement in the economic organization of the agricultural sector. Agricultural development is important because it raises the incomes of the mass of the people in the countryside; in addition, it increases the size of the domestic market for the manufacturing sector and reduces internal economic disparities between the urban centres and the rural districts (World Development Indicator, 2006).

Modern mechanized farming is very important to meet the requirements of the ever increasing population with its higher purchasing power, agriculture increased its outputs and productivity, a process which had consequences for the price of agricultural products. The more people live in the cities and have to buy food at the market, the more agricultural prices became a political issue. The interest of urban society in agriculture is an interest in low prices, and the request of the primary sector for price increases is a regular nuisance for the urban population. The increase in output and productivity of agriculture could only be achieved by division of work and specialization. Until date, only part of the production process takes place on the farm, while, in addition, agriculture uses industrial products like fertilizer, pesticides, machinery and equipment, the services of the tertiary sector like banking, insurance etc. and hands its products over to other sectors for packing, processing, or distribution. Today, agriculture is deeply interwoven with other sectors of the economy (Kuhnen, 1978).

Therefore, changes in agriculture bring with them new tasks in training and research which can only be provided by universities, not only within the State but Nationwide. The process of agricultural production has become increasingly complex and requires therefore scientific help in research and extension. The need for optimizing the allocation of inputs has given agricultural economics importance, especially in the field of farm management. Necessary changes in the agrarian structure require special studies. The application of inputs in agriculture has created new tasks in fields like agricultural chemistry and engineering, and the processing of food has become a new area of specialization. Such a highly differentiated organization of agriculture requires professional associations. Finally, the provision of food for the population with so many contributors and interest-groups can be achieved only with a functioning marketing and distribution system as well as a sound agricultural policy (Kuhnen, 1978).

For all these tasks, persons have to be trained, and research has to provide the necessary scientific basis. The changes in agriculture have broadened the role the universities have to play as training and research institutions. 


\section{The Functions Of Universities In Modern Society}

Conventionally, the functions of universities are teaching and research. In their teaching activities, universities provide the professional training for high-level jobs, as well as the education necessary for the development of the personality. University research increased the body of theoretical knowledge as well as its application to practical problems.

The traditional university restricted itself mainly to a close circle of professors and students from the upper strata of society and lived in relative isolation, the proverbial, "Ivory Tower". It produced the elite of the nation, and society had to adopt to the elite. Research was the privilege of the professors, determined to a large extent by personal interests and their contacts among each other. We all know of the brilliant performance of this traditional university which laid down the basis for the progress of mankind. But too much concerned with itself, this university lost contact with society until it was completely isolated and did not understand the issues of its surroundings. This, however, meant a reduction in performance. The ultimate yardstick for measuring the success of a university is the improvement in the lives of the people it serves. The full benefit from a university can be obtained only if the university and society are organically linked together. Expressed differently, the needs of society have to be at the center of a university's activities, and a flexible adjustment to changing needs is necessary but lacking. This trendy phenomenon is not peculiar to Nigerian universities alone, but is more or less the take all over the world (Kumar, 1988).

The present universities in developing countries were established to cater for and satisfy the needs of that time. Today, in many industrial countries, the cogent issue is to open up the elite university to the masses of young people and to adjust to today's democratic, pluralistic society, and at the same time try to adhere to the benchmark of teaching and proper ethics of research (Kuhnen, 1978).

In this regard, one cannot deny the truth that universities in this country, Nigeria, have been built more or less in accordance with colonial models and in many cases designate as branches of the British institutions. However, the subjects and methods of science correspond to the society in which they were generated; for example, these Western-oriented universities meet the interests of present and past Western industrial societies. Likewise, research activities (projects) and methods and their applications are centered around Western problems, needs, and conditions. As a result, universities all over the world are faced with the same transition, from being universities for only a few, to universities for many. But, it must be underscored at this juncture that the universities in developing countries, particularly Nigeria, face additional responsibilities, which is to cater for the needs of the immediate society where they are located.

\section{Rural Development Through Local Approaches}

The discussion in this paper is centered on agricultural development and the role of resident universities, however, we must understand that there is no way we can separate agricultural development from rural development. Therefore, new thinking on rural development stressed concepts and approaches such as community participation, empowerment, and sustainable livelihoods in the broader context of poverty reduction. Many countries are drawing up poverty reduction strategies with the cooperation of involved sectors, and international funding is becoming available to implement these strategies. Thus, stakeholders in community development are currently renewing their efforts towards rural development with fresh insights into the key factors that militate against rural development and poverty reduction.

Atchoarena and Sedel (2003) highlighted that a comparative review of contemporary ideas in rural development and education shows much convergence. Currently, both domains are aware of similar intervention principles, including: focusing on poverty reduction; recognizing the potential of indigenous knowledge; promoting the use of participatory approaches; emphasizing community involvement; coping with the withdrawal of the state from direct support within the context of structural adjustment programs and liberalization policies; adopting a holistic view of the development of the rural space; preparing rural people for off-farm employment by building knowledge and skills capacity; understanding the complementarity of urban/rural linkages; developing partnerships with NGOs and civil society; mainstreaming gender issues; and focusing on HIV/AIDS issues.

The current attention to rural development and poverty reduction constitutes a real challenge to the providers of education and training, including universities. Unlike previous attempts to deal with rural development, the current view is that the "rural" is more than agriculture and that rural development concerns all those who live in the rural space and those in urban areas who have close links with rural activities and influences (Atchoarena \& Holmes, 2004).

Beyond its traditional role, universities have an opportunity, in cooperation with other stakeholders, to enrich and support other levels of education with critical knowledge and information on agriculture and natural resource management, which can be of important benefit in the pursuit of rural development, poverty reduction, and food security. 
Additionally, in the government's attempt at increasing decentralization, local development is receiving growing attention. Local development initiatives give community representatives the opportunity to work together to improve the local economy. In depressed areas, such as flood prone zones and regions, these initiatives focus on economic revitalization and sustainable growth. Local development strategies are often centred on partnership and consensus-building in identifying development needs and launching economic development initiatives. Among the key actors in such approaches focusing on the local economy and labor market, are the educational institutions, such as, universities (Atchoarena \& Holmes, 2004).

Importantly, how communities deal with these changes depends not only on the "delivery" of services, the maintenance of infrastructure and economic development. It also relies on local people using assets in new ways, working cooperatively, improving networks, mobilising existing skills, and putting innovative ideas into action. The outcomes are not only jobs, income and infrastructure but also strong functioning communities, better able to manage change. In turn, successful processes of community development involve not just funding, attracting new employers, or new infrastructure. Passion, enthusiasm, commitment, local "animateurs", small visible successes, inventiveness and cooperation collectively drive self-directed development (Cavaye, 2001).

\section{What Makes Community Developed?}

Ideally, development is the creation of wealth, and wealth in terms of the things that people value and cherish (Shaffer, 1989). This development entails ongoing economic, social and environmental improvement, that is, sustaining a desirable environment; having a vital social system that fosters collaboration, equity and freedom; and a vital economy that is diverse, competitive and accessible (Christenson et.al., 1989). Development increases choices, sustains positive attitudes, improves the function of institutions and enhances quality of life.

Development within rural and regional communities depends on several interdependent components. First, information is the lifeblood of any society and vital to the activities of both the government and private sectors. Bell (1974) holds the view that "the dependence upon information to create innovation and change, places a high premium on the ability of (developing countries) nations to access and use information to create advances in society". The development of countries globally cannot be achieved without the development of the rural community. This is because 75 to 80 percent of the people in developing countries live in the rural areas need positive, relevant and prompts attention in their daily activities. Second, adequate infrastructure is needed to support economic activity and community life. Third, a healthy economy depends in part on new business starts, access to venture capital, improving the efficiency of existing firms or the establishment of new industries or enterprises. Fourth, policy settings can help position rural and regional areas in an economically competitive, socially just, and environmentally responsible position. Fifth, the delivery of services in rural communities allows the local economy and social system to function, sustaining employment, population and quality of life in rural areas.

Indeed, investments in infrastructure or major business development, such as, irrigation development, transport infrastructure, or industrial development have transformed some local economies. But lasting development within rural communities also relies on less tangible components of development, such as community ownership, local leadership, action, "rethinking" and motivation. Indeed, the "concrete" benefits of community development, such as employment and infrastructure, often come through local people changing attitudes, mobilising existing skills, improving networks, thinking differently about problems, and using community assets in new ways.

These less tangible aspects of vital communities are both the means and the ends of community development. Rural community development fundamentally involves a process - a series of actions and decisions - that improves the situation of a community, not just economically, but also as a strong functioning community in itself. It is through action, participation and contact that the community becomes more vital, more able to manage change with stronger networks, organizational ability, skills, leadership and passion.

\section{The Role Of Universities Of Agriculture}

Traditionally, many agricultural universities in developing countries have defined their primary mission as one of serving as a source of science and technology for increasing food and animal production. This emphasis alone, neglecting as it does major and critical features of the development process, has increasingly isolated the university from its environment. Some universities have sought to break out of the narrow confines of a production technology focus and are beginning to address major resource and system domains, such as watershed management, soil conservation, integrated pest management, extension education, and farming systems. Finally, a few universities are beginning to address larger policy and institutional questions related to marketing, rural-urban interactions, agro-industry linkages, and employment and income generation. Despite the need and desire to move to a more comprehensive mission and role, many universities are still burdened with a fixed set of ideas and assets that reflect a relatively narrow focus on production. Overcoming this legacy is a 
difficult struggle for many universities. To succeed they must begin to explore opportunities and to envisage future roles that are significantly different from just doing more of the same (Hansen, 1989).

Traditionally, universities, including agricultural universities, have focused most of their attention on national development through the two missions of research and teaching. Universities have often seen themselves as institutions to prepare graduates for national and international labor markets, and to address research problems. Academics have had to win national and/or international acclaim for the quality of their research and teaching, and this has sometimes been at the expense of making a greater contribution to local economies and communities. Only a small share of the university community appears to have developed strategies to contribute to the development of community education and to support local development (Atchoarena \& Holmes, 2004).

Furthermore, higher education and basic education have coexisted with relatively little interaction. Despite the impact of the quality of university teaching and research on the state of the educational system of a country, there has been a tendency for universities to pay little attention to the primary and secondary levels of the school system. Even university departments of education have sometimes needed encouragement to develop partnerships for educational research and teacher placements with local schools (Atchoarena \& Holmes, 2004).

Yet, it is increasingly recognized that all types and levels of education other than basic education, including higher education, must contribute significantly to the pursuit of Education For All (EFA) goals. Notably, the World Conference of Higher Education (1998) proclaimed that one of the missions of higher education is "to contribute to the development and improvement of education at all levels". In the context of formulating lifelong learning policies, and crafting more coherent, seamless, and flexible education and training systems, universities are likely to have an important role to play in supporting teaching and learning at all levels. Yet, the extent to which universities already support basic education and the nature of this support are not well known. In some countries, universities play a much greater role in supporting basic education than in others (cited in Atchoarena \& Holmes, 2004).

\section{University-Industry Relationship}

Studies have proven that university-industry relationship is not a new phenomenon. For example, Germany was one of the pioneering countries where university industry relationship helped create the pharmaceutical industry in the early 19th century. Also, the United States has taken an active role in developing and fostering university industry collaboration. There are many mutual benefits to a close relationship between a university and an industrial firm. Firms gain access to not only leading edge technologies, but also highly trained students, professors and university facilities. A firm can gain prestige and acceptance in its stakeholder community though its association with a prestigious university. Universities can augment their funding sources by working with the industry. This has become an increasingly important consideration in most countries as public source of funding for higher education has become scarce. Costs of operation of institutions of higher education have outpaced the other indices of price increase. University administration feels the pressure to supplement their funding by various means, one of which is of course sponsored research. Working with the industry provides other pedagogical and academic value to the students and faculty. Faculty and students can keep up with the practical problems and gain access to knowledge developed outside the university. This is particularly important in many emerging fields where academic research and publication usually lags industry (Chakrabarti \& Rice, 2003).

Research has shown that industry-university collaboration may take several forms, however, the National Science Foundation in the US identifies four inter-related components in the university-industry relationships, namely: research support, cooperative research, knowledge transfer and technology transfer. Research support involves contributions of both money and equipment to the universities by industry. This type of contribution is valuable as it provides great flexibility to upgrade laboratory and develop programs in certain areas of interest. Although corporate support of universities has been unrestricted in the past, it is more common now to have these funds targeted for specific purposes. Universities have developed many cooperative research consortiums with industry to pursue research and development in some common areas of interest. In the United States, the National Science Foundation has actively promoted such formation of cooperative research through establishment of Engineering Research Centers (ERC) and Industry University Cooperative Research Centers (IUCRC). These centers provide formal structures to advance technology through various types of collaboration between a university and industrial firms (Chakrabarti \& Rice, 2003).

Knowledge transfer involves many activities that include both formal and informal means of communication, interactions and personnel exchanges at student and faculty levels. Involvement of the firms in the academic programs of the universities is a major mechanism for knowledge transfer. Often students work on corporate problems for their theses and dissertations in many technical universities in Finland. Cooperative education programs, internships and job placements for students and recent graduates provide means for knowledge transfer. Technology transfer is generally based on the collaborative research with the industry. The 
Department of Agriculture in the United States developed the agricultural extension service model for transferring agricultural technology to the farmers where the universities were key sources of information. The concept of "land grant" college was developed by an act of the US Congress in 1862 for "agriculture and mechanic arts, scientific and classical studies, and military tactics for the liberal and practical education of the industrial classes." Major public universities in the US have been established as land grant institutions with a clear mandate for knowledge and technology transfer. From that tradition, different models of interaction with the industry have evolved. Universities have taken active roles in establishing various types of organizations, such as business incubators, science parks, technology parks, etc. to foster entrepreneurship and business development.

Rice (2002) has shown the effective mechanisms for assisting entrepreneurs in business incubators. This study shows that it is a complex process and depends on the strategic objectives of the entrepreneurs, their capabilities as well as managers of these incubators. Location in a business incubator offers great opportunity of networking as well as tapping the resources available at the sponsoring organization, often the university. The traditional view of the business incubator is overly focused on capital and infrastructure related resources. Our study in Finland shows that knowledge exchange is very important in developing unique value in universitylinked business incubators.

\section{Funding Agricultural Research: Roles Of Government, Public And Private Institutions}

Ensuring an adequate and constant source of funding for university research activities must not be taken jokingly. Government, public and private funds support research at different levels. The future of research and, thus, the scale to which universities can contribute to the development of agriculture, depends on the amount of financial resources doled out to them by the government, public and private institutions in the Country. It is agreeable that research is expensive to embark on, and the more sophisticated the research projects are, the higher the costs, especially in science fields. This is a general phenomenon and Nigeria is exceptional, even the situation becomes tougher, especially for private universities which cannot readily rely on the government budget. Universities usually face these problems when they develop from the undergraduate to the graduate level. With the introduction of graduate training, research is no longer a hobby of the professor, but an integral part of the activities of the university because graduate-training is training in, and by, research.

Governments and governmental institutions will partly have to step in and contribute to the research funds, perhaps by special contracts by means of which they tap the resources of equipment and expertise to get part of their research requirement done. With a view to the amount of the needs of research and the limitations of resources, a type of co-operation between governments and universities should be possible which gives governments the necessary control over the use of their funds and the universities the necessary freedom within a frame-work agreed upon research contract.

Additionally, governments are not the only possible research contractors. Numerous small and medium food and agro industries cannot afford a research department like big companies, but require research to improve their products, production processes, quality controls, etc. Here, ways and means of co-operation have to be developed for mutual benefit. If, for instance, graduate students take over such assignments with guidance from their professors and payment from the industries, not only are the scholarships for the graduate students and the research costs for their theses taken care of. This research, by necessity, is related to practical problems and the student is introduced to problems of his possible future working place. Again, problems of independence and research ethics have to be solved, but such arrangements might help financing research, while such research is at the same time a contribution towards economic development.

According to King, Toole and Fuglie (2012, p. 2), the U.S. agricultural research system receives funding from three primary sources: (1) Federal appropriations, (2) State appropriations, and (3) nongovernment sources (mainly private-sector firms but also charitable foundations). These funds support research that is carried out by three main types of institutions: (1) Federal research facilities; (2) State-affiliated land-grant universities, State Agricultural Experiment Stations (SAES), and other cooperating institutions such as schools of forestry, veterinary schools, and 1890 and 1994 land-grant institutions; and (3) private laboratories and experimental sites, nearly all of which are owned and operated by non-governmental and for-profit firms.

Private institutions include firms in the food manufacturing, chemical, equipment, pharmaceutical, seed, and biotechnology industries that provide inputs to the farm sector and process agricultural commodities. Federal research facilities receive funding almost exclusively through Federal appropriations, with a small contribution (less than 1 percent) from firms through Cooperative Research and Development Agreements and other arrangements. Firms performing agricultural R\&D fund nearly all of it themselves, receiving very little funding from public sources except for Small Business Innovation Research grants and research contracts. By contrast, universities, SAES, and other State institutions draw on Federal, State, and private funds to support their R\&D. According to USDA (2007), Federal funds from USDA and other Federal agencies typically support 
50 to 60 percent of the agricultural R\&D at State institutions, and State-level appropriations support roughly another third. Non-government sources of funds - including research contracts from private firms, technology licensing fees, and foundation grants - provide the remaining 20 percent of research funding for these State institutions (King, Toole, \& Fuglie, 2012).

Undoubtedly, the costs of research can vary greatly, according to the way it is conducted. Whenever feasible, research in crop production, for instance, is cheaper than research in animal production. For universities and other agriculture institutions, many research objects require fields for experiments, cultivation tests, blood and semen test for animals, etc. Instead of buying expensive land for university farms, arranging experiments in the villages on the peasants fields is much cheaper, even when the peasants receive compensation. At the same time, experiments are more related to the real world. But, such arrangements are not feasible for all types of research. The question of a university of agriculture's contribution to the needs of society is not completely dealt with without some comments on the extension of results from research work. While in industrialized countries a highly developed infrastructure links the universities with other public and private institutions and guarantees the immediate spread of new knowledge and research findings, this sort of infrastructure does not exist in developing countries, Nigeria for example, at least not to the extent required. Therefore, universities do not readily turn into an agent of socio-economic development, and special measures are necessary improve on this situation. A spectrum of possibilities like publications, public lecturers, training courses, newspaper articles, etc. are available to assure that universities' findings are passed on to society as soon as possible. Likewise, interpretation of findings to rural farmers is paramount as research findings are often written and coded in jargons only understood by individuals and professionals in the area (Kuhnen, 1978).

\section{The Way Forward}

In light of the discussions above, this paper proposes the following suggestions as the way forward for agricultural development as a true means of poverty alleviation in Nigeria:

1) Universities in Nigeria should build strong linkages with the government, and any other critical constituencies and policy arenas to ensure that research and educational, and rural community development agendas are entirely demand - rather than supply-driven.

2) Universities should develop a continuous process of strategic planning to enhance the agriculture research and use same to further development of rural communities in the State.

3) Universities must design strong, integrated programs and organizational structures as a countervailing influence against disciplinary fragmentation. The trend in academic is now moving speedily towards multidisciplinary.

4) Universities should endeavour to adopt more holistic learning approaches, even it means teaching students in their local or indigenous languages.

5) Last but not the least, is the necessary evil that universities should endeavour to secure their own autonomy from government controls in order to enhance university innovation in research and education in areas that they deem productive to local and rural community developments in Nigeria.

\section{Conclusions}

In conclusion, universities can play many important roles in terms of their intellectual leadership for agriculture and their contribution to learning and knowledge generation. However, it is also clear that policymakers can look to universities to be more proactive in further developing their outreach and extension services for the benefit of the education of rural people.

A major challenge for higher education institutions serving rural areas is to be able to combine local relevance and international standards. Besides attending to problems of significance, universities can potentially become showcases of local traditions and knowledge, reflecting the regional, cultural, and ethical traditions of their society, as well as global movements and forces.

Although it is not easy for universities to think in terms of both their universal mission of knowledge production and their contribution to the development of local communities, the experiences described suggest some possibilities for the future. Increasingly, universities are developing strategies to intensify and widen their contribution to learning and development for rural people. In addition to their roles in curriculum development and training teachers and trainers, universities play an essential role in conceptualizing development problems and policies. They can contribute in a variety of ways to supporting education in local communities and regions as well as supporting rural development initiatives. Universities can potentially make a greater contribution to the prospects of depressed, relatively neglected rural communities. Universities can also provide access to lifelong learning to rural people. However, to fulfill their roles as contributors to a culture of learning and rural development, universities need to engage more directly and more effectively in partnerships and dialogue with other local educational institutions and their surrounding communities. 


\section{References}

[1]. Agboola, A.K. (2013). Nigeria Millennium Development Goals: Can Revisiting Agriculture Help In Poverty Reduction And National Economic Development? Paper presented at the International Multidisciplinary Conference on Research, Developments and Practices in Science, Technology, Education, Arts, Management \& the Social Sciences (iSTEAMS) at the University of Ibadan on $30^{\text {th }}-1^{\text {st }}$ June, 2013. Book Of Proceedings, Proceedings Series 4, pp. 27-36.

[2]. Atchoarena, D. \& Holmes, K. (2004). The Role of Agricultural Colleges and Universities in Rural Development and Lifelong Learning in Asia. Asian Journal of Agriculture and Development, Vol. 2, Nos. 1\&2. Paper presented at the 15th Conference of the Asian Association of Agricultural Colleges and Universities, held in Nagoya, Japan on 27-30 September 2004. Retrieved June 1, 2013 from ftp://ftp.fao.org/docrep/fao/010/ai436e/ai436e.pdf

[3]. Bell, D. (1979). Communication technology: For better, for worse. Harvard Business Review, Vol. 57, issue 95, No. 4.

[4]. Cavaye, J. (2001). Rural Community Development - New Challenges and Enduring Dilemmas. Cavaye Community Development. Paper presented at the Shaffer Symposium, University of Wisconsin, USA 2001 and published as Cavaye J.M. (2001) Rural Community Development: New Challenges and Enduring Dilemmas. The Journal of Regional PolicyAnalysis Vol 31, No. 2, pp. 109-124. Retrieved June 10, 2013

fromhttp://www.communitydevelopment.com.au/Documents/Rural\%20Community\%20Development\%20$\% 20$ New\%20Challenges\%20and\%20Enduring\%20Dilemmas.pdf

[5]. Chakrabarti, A. \& Rice, M. (2003). Changing Roles of Universities in Developing Entrepreneurial Regions: The Case of Finland and the US. MIT IPC Working Paper IPC- $\quad 03-003 \quad$ September 2003. Retrieved June 5, $2013 \quad$ from http://web.mit.edu/ipc/publications/pdf/03-003.pdf

[6]. Christenson J.A., Fendley, K. and Robinson J.W. (1989). Community Development. In Community Development in Perspective, edited by J.A. Christenson and.W. Robinson, pp. 3-25. Ames: Iowa State University Press.

[7]. Gary E. Hansen, G.E. (1989). Universities For Development: Lessons For Enhancing The Role Of Agricultural Universities In Developing Countries. A.I.D. Evaluation Occasional Paper No. 31. U.S. Agency for International Development, August 1989. Retrieved June 5, 2013 from http://pdf.usaid.gov/pdf_docs/PNABC900.pdf

[8]. Harande, Y.I. (2009). Information Services for Rural Community Development in Nigeria. Library Philosophy and Practice 2009. Retrieved June 10, 2013 from http://www.webpages.uidaho.edu/ mbolin/harande.htm

[9]. Hansen, G.E. (1989). Universities For Development: Lessons For Enhancing The Role Of Agricultural Universities In Developing Countries. U.S. Agency for International Development. A.I.D. Evaluation Occasional Paper No. 31 , August 1989.

[10]. King, J., Toole, A., \& Fuglie, K. (2012). The Complementary Roles of the Public and Private Sectors in U.S. Agricultural Research and Development. Economic Brief Number 19, September 2012

[11]. Korten, D. C. (1980). Community Organization and Rural Development: A Learning ProcessApproach. Public Administration Review, Vol. 40, No. 5 (Sep. - Oct., 1980), pp. 480-511. Retrieved June $10, \quad$ from http://courses.washington.edu/pbaf531/Korten_LearningProcessApproach.pdf

[12]. Kuhnen, F. (1978). The Role of Agricultural Colleges in Modern Society- - The University as an Instrument in Social and Economic Development - Zeitschrift für ausländische Landwirtschaft, 17. Jahrgang, Heft 2, April - Juni 1978, pp. 77- 88. Retrieved June 10, 2013 from http://www.professor-frithjof-kuhnen.de/publications/agricultural- colleges/2.htm

[13]. Kumar, D. (1988). The Challenges of Rural Development Summarizing the Real Problems of Rural Communities and Example of How Universities Have Responded to the Challenges. In What Can We Do for Our Countries? The Contribution of Universities toNational Development. Commonwealth Universities in Congress, Perth, Western Australia, February, 1988, pp. 457-465.

[14]. Meijerink, G. \& Roza, P. (2007). The role of agriculture in economic development. Document Transcript. Markets, Chains and Sustainable Development Strategy \& Policy paper 4. Retrieved October $11^{\text {th }}, 2012$ from

[15]. http://www.slideshare.net/majesticmaths/agri-economy

[16]. Rice, M.P. (2002). "Co-production of business assistance in business incubators: An exploratory study" Journal of Business Venturing, 17: 163-187

[17]. Shaffer, R.E. (1989). Community Economics: Economic Structure and Change in Smaller Communities. Ames: Iowa State University Press.

[18]. The World Bank (2008). World Development Report 2008: Agriculture for Development. The UK Food Group. Retrieved October 17, 2012 from www.worldbank.org/wdr2008

[19]. U.S. Department of Agriculture, National Institute of Food and Agriculture (2007). Inventory of Agricultural Research. Current Research Information System.

[20]. World Development Indicators (WDI), (2006). Retrieved February 10, 2013 from http://devdata.worldbank.org/wdi2006/contents/index2.htm 